Gitation: Ramírez-Rojas, S. G., Pérez-González, J. O., VázquezAlvarado, J. M. P.,\& Palacios-Talavera, A. A. (2021). Trichoderma harzianum in vitro mycoparasitism on Peronospora belbahrii in basil (Ocimum basilicum). Agro Productividad. https://doi.org/10.32854/ agrop.v14il1.1949

Editor in Chief: Dr. Jorge Cadena Iñiguez

Received: February 5, 2021

Accepted: October 19, 2021

Published on-line: December 1, 2021.

This work is licensed under a Creative Commons Attribution-NonCommercial 4.0 International license.

\section{Trichoderma harzianum in vitro mycoparasitism on Peronospora belbahrii in basil (Ocimum basilicum)}

\author{
Ramírez-Rojas, Sergio G. ${ }^{{ }^{*}}$; Pérez-González, Jesús O. ${ }^{2}$; Vázquez-Alvarado, Jorge M. P. ${ }^{1}$; \\ Palacios-Talavera, A. Alejandro' \\ 1 Instituto Nacional de Investigaciones Forestales, Agrícolas y Pecuarias. Campo Experimental Zacatepec, \\ Carretera Zacatepec-Galeana km 0.5, Zacatepec, Morelos, México, C. P. 62780. \\ 2 Universidad Tecnológica del Sur del Estado de Morelos, Carretera Puente de Ixtla-Mazatepec km 2.35, \\ Colonia 24 de febrero, Puente de Ixtla, Morelos, México, C. P. 62665. \\ * Correspondence: sergioinifap@yahoo.com.mx
}

\begin{abstract}
Objective: To describe the symptomatology and to identify the mildew causal agent in basil (Oscimum basilicum), as well as the Trichoderma harzianum-Peronospora belbahrii in vitro mycoparasitic activity.

Design/methodology/approach: Samples were taken from Nufar basil cultivars that had been naturally infected by mildew and, afterwards, the causal agent was isolated in order to carry out a pathogenicity test. The T. harzianum-P. belbahrii parasitism stages were observed in samples from the area in which both microorganisms interact.

Results: The disease symptoms that reveal the presence of a mildew causal agent on basil plants grown in pots and soil match Peronospora belbahrii. Subsequently, the Trichoderma hyphae rolled up and penetrated and vacuolated the conidiophores and the pathogen mycelium.

Study limitations/implications: This study was carried out using only one variety of basil.

Findings/conclusions: T. harzianum's capacity to parasitize $P$. belbahrii in vitro was observed after $72 \mathrm{~h}$. Once the conidium of the antagonist germinated, the hyphae directed their chemotropism growth towards $P$. belbahrii's conidiophores and mycelium.
\end{abstract}

Key Words: Biological control, Trichoderma, Confrontation test.

\section{INTRODUCTION}

Basil (Ocimum basilicum) is grown throughout the world and is mostly used by the gastronomy and make up sectors, as well as for therapeutic purposes (Martínez et al., 2016). In Mexico, 49,460 ha are used for its production, obtaining a 9.63 $\mathrm{t} \mathrm{ha}^{-1}$ estimated yield. This crop has been traditionally grown in the following states: Baja California, Morelos, Nayarit, and Baja California Sur (SAGARPA, 2015). Fungal diseases have a major impact in basil crops. These diseases appear mainly during months with heavy rainfall, heat, and cloudy days. Therefore, producers must pay attention and monitor the crops (Briseño, 2013). Mildew (Peronospora belbahrii) is the main disease that affects basil worldwide (Saude $e t$ al., 2013; Choi $e t$ al., 2016). Belbahrii et al. (2005) and Thines et al. (2009) called this disease Peronospora belbahrii and they classified it in the Kingdom Chromista, Order Personosporales, and Family Peronosporaceae. 
Mildew is considered a biotrophic and polycyclic parasite; the conventional alternatives for its handling include the use of tolerant varieties and the application of cyazofamid (Ranman), mandipropamid (Revus), azotrystrobin, mefenoxam, and mandipropamid (Homa et al., 2014). However, this pathogen can develop resistance to fungicides, especially mefenoxam (Cohen et al., 2013; Collina et al., 2016). The toxic residues and the limited availability of fungicides make it difficult to exercise a chemical control of downy mildew (Gisi and Leadbeater, 2010). Therefore, we need to find different techniques that will allow producers to efficiently handle the disease. In this regard, biological control is a viable alternative to decrease the impact of $P$. belbahrii in basil plantations. Species from the Trichoderma genus have shown an efficient control of phytopathogenic fungi. Trichoderma inhabits the rhizosphere zone, protects plants from pathogens through competition, mycoparasitism, and antibiosis (Lorito et al., 2010; Druzhinina et al., 2011). It has shown positive responses in the control of Alternaria alternata (Sempere and Santamarina, 2007), Pseudoperonospora cubensis (Martínez et al., 2011), and Didymella bryoniae (Martínez et al., 2013).

The application of T. harzianum in the soil reduced Fusarium proliferatum in onion (Allium cepa) crops by 25\% (Ghanbarzadeh, 2016). The seeds of different varieties of tomato (Solanum lycopersicum) were inoculated with T. harzianum to control Pythium spp. (Majorie et al., 2016). The objective of this study was to describe the mildew symptomatology and its causal agent in basil crops, as well as the T. harzianum in vitro mycoparasitism on P. belbahrii.

\section{MATERIALS AND METHODS}

\section{Symptomatology and identification of the mildew causal agent on basil}

The pathogen used for this study was isolated from Nufar basil cultivars sowed on June 2016, which had been naturally infected. The productive areas in which that crop was grown were located in the State of Morelos, Mexico, between Puente de Ixtla and Mazatepec $(\mathrm{km} 3.5)$, between parallels $18^{\circ} 27^{\prime}$ and $18^{\circ} 43^{\prime} \mathrm{N}$ and meridians $99^{\circ} 11^{\prime}$ and $98^{\circ} 23^{\prime} \mathrm{W}$, at 967 masl. A macroscopic description of the symptoms and typical signs of the disease in field conditions was carried out. Sprouts from infected plants were selected and sent to the Quality Herbs lab. Twenty-five subsamples were observed to develop the microscopic characterization. These structures were observed in a Nikon optical microscope, using a 40x magnification.

In order to carry out a pathogenicity test, sporangia from basil leaves infected with $P$. belbahrii were obtained. The infected leaves were immersed in cold sterile water $\left(10^{\circ} \mathrm{C}\right)$, and their underside was gently rubbed with a spatula. A sporangium watery suspension with a $3.7 \times 10^{5}$ sporangium per $\mathrm{mL}$ concentration was obtained. This concentration was determined using a quantitative dilution method and counting spores and sporangium with a $0,100 \mathrm{Mm} / 0,0025 \mathrm{Mm}^{2}$ Neubauer Improved Marienfeld camera. The solution was sprinkled on the upper side and underside of the leaves, using a 1.5-L Matabi hand sprayer. The leaves belonged to 20 Nufar basil cultivar plants; they were 45 days old and were grown in $17.5 \mathrm{~cm}$ (diameter) $\times 13.5 \mathrm{~cm}$ (height $) \times 13 \mathrm{~cm}($ depth $)$ pots. The pots contained a sterile substrate (solarization) with a 1:1:1 rate of arable land, atocle (sandy, humid, and fertile soil, rich in humus), and compost. They were watered until soil saturation was 
achieved and they were placed in $50 \times 70 \mathrm{~cm}$ polyethylene transparent bags. The bags were sealed to keep a 90-100\% relative moisture; the average temperature reached $32 \pm 2{ }^{\circ} \mathrm{C}$ and $22 \pm 2{ }^{\circ} \mathrm{C}$ during the day and at night, respectively (Risco et al., 2018; Zhan et al., 2019). Regarding their morphological identification, the dichotomous keys developed by Clements and Shear (1931) and Thines et al. (2009) were used to identify their genus and species, respectively. Additionally, other researches were consulted to compare the information about the symptoms, signs, and reproductive structures of the natural infection and the artificial inoculation.

\section{In vitro mycoparasitism of $T$. harzianum on $P$. belbahrii}

A Bioxon PDA (Potato-Dextrose-Agar) culture medium placed in 90mm Petri dishes was used to describe T. harzianum's mycoparasitism on P. belbahrii. A modification of the dual confrontation test described by Martínez and Solano (1994) was carried out: a $25 \mathrm{~mm}^{2}$ fragment of basil leaves was placed in each of the 20 Petri dishes; these leaves had a 30\% P. belbahrii infection; they were placed on the culture, 1 centimeter away from both the edge of the Petri dish and the pathogen. Afterwards, T. harzianum was applied (Aislamientos de la Universidad Tecnológica del Sur del Estado de Morelos, isolated in Tehuixtla, Puente de Ixtla, Morelos). Five Petri dishes in which the antagonist was not inoculated were designated as control. Once the Petri dishes were inoculated, they were placed in an incubator at $25 \pm 2{ }^{\circ} \mathrm{C}$ for $96 \mathrm{~h}$. In order to observe the hyphae interaction - coiling by hyphae, penetration, vacuolation, and lysis-, three samples were taken from the contact area of both fungi per repetition (Petri dish), were placed on a microscope slide with lactophenol and were observed using a Nikon Optical Microscope, with a 40x magnification.

\section{RESULTS AND DISCUSSION}

\section{Symptomatology and identification of the mildew causal agent on basil}

Under controlled conditions, the symptoms and signs of downy mildew first appeared $18 \mathrm{~h}$ after the inoculation. Under both conditions (controlled and in the open fields), the symptoms and signs (Figure $1 \mathrm{~A}-\mathrm{B}$ ) were found on the older leaves in the middle of the plant, from where they spread to the leaves on the higher part of the plant. The leaves underwent chlorosis and had irregular stains that became dark brown and then black as the stain grew older. Cohen et al. (2013) and Wyenandt et al. (2015) pointed out that the chlorotic injuries of the leaves gradually turned necrotic. The first signs (a whitish sporulation) appeared on the underside of the leave; when the temperature started to raise above 30 ${ }^{\circ} \mathrm{C}$, the sporulation turned dark brown and black (Figure 1-B). The reproductive structures changed color immediately after the first sunbeams and when there was morning dew or it had rained. Under lab conditions, Cohen and Ben-Naim (2016) determined that P. belbahrii started infecting the leaves just after four hours of unchecked moisture. A severe impact can be seen in the underside of the leaves (Figure 1-C). The pathogen showed hyaline and monopodial sporangiophores, emerging from the stroma located on the underside of the leaf. Dichotomously branched in an $<90^{\circ}$ angle, the upper side showed six submonopodial 
branches. The higher branches were curved and pointed, with curved sterigmata (one long and other short).

The zoosporangia had a slightly ovoid shape, with a round base and were chestnut brown or a darker color (Figure 1-D-E). Cohen et al. (2013) and Wyenandt et al. (2015) described dark purple and ovoid spores. The morphological description of the element isolated in the State of Morelos matched the description of Peronospora belbahrii made by Thines et al. (2009), Grabowski (2012), Bastidas et al. (2016), Cohen et al. (2017), Risco et al. (2018), and Zhan et al. (2019). According to the observation of the symptoms in plants grown in pots and in the field, the pathogenicity test showed that Peronospora belbahrii is the mildew causal agent of basil in the study area.

\section{In vitro mycoparasitism of $T$. harzianum on $P$. belbahrii}

The Trichoderma colonies placed in the PDA culture medium were originally white, but turned dark green three hours later (Figure 2-A). Their phialides were bottle-shaped: they had a small base, a swollen middle, and a narrow apex. Most of them were divided into 2-3 whorls. Their mycelium was thin and slender; their hyphae had septa with smooth walls. The conidiophore had narrow, curved branches with a main axis (Figure 2-B).

T. harzianum colonies have grey to green mycelia; the edge of their growth area is white; they have narrow conidiophores and ampulliform phialides; they have a narrow base, a swollen middle section, and a thin apex. They have subglobal, ellipsoidal conidia and elliptical chlamydosphores (Ellis, 2006; Samuels et al., 2007; Chaverri et al., 2015; Wang et al., 2016).
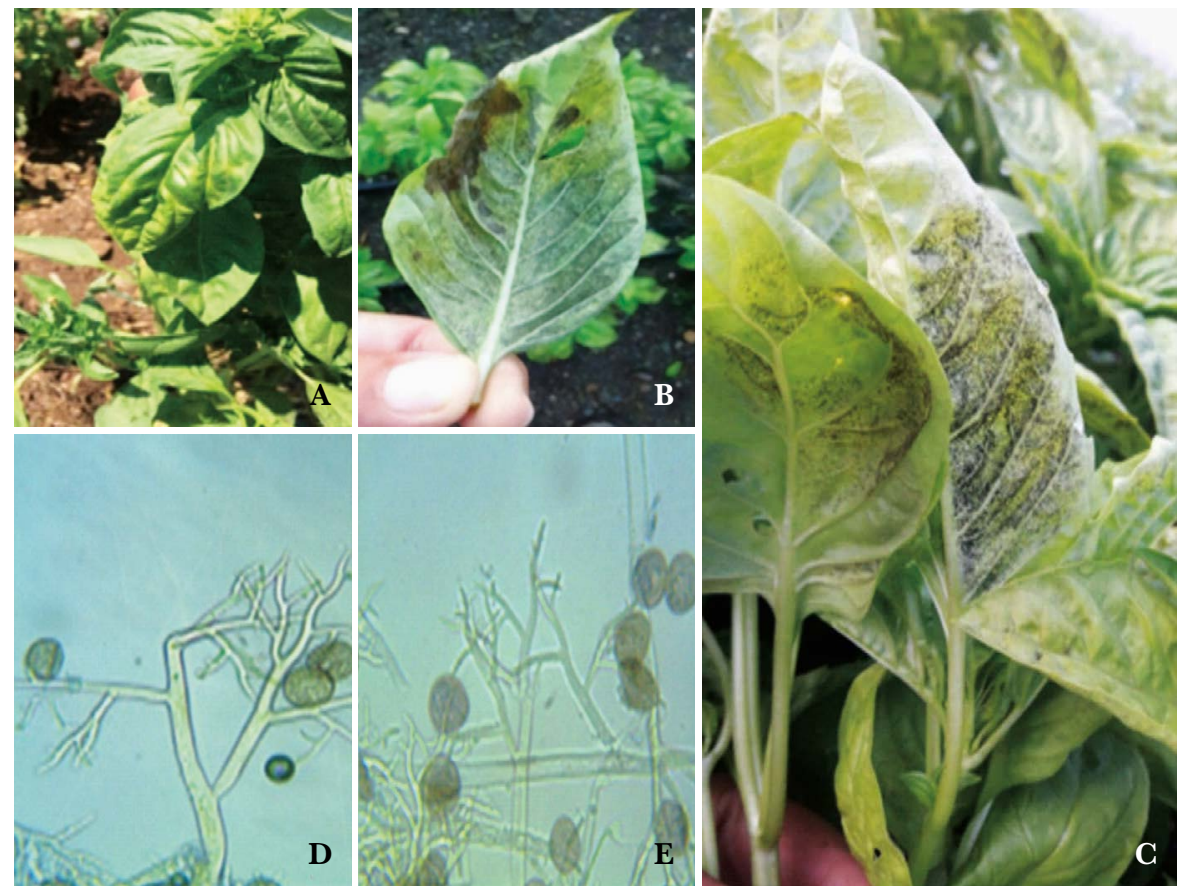

Figure 1. Signs of mildew symptoms in basil plantations (A); presence of signs on the underside (B) and upper side of the leaves $(\mathrm{C})$; microscopic observations at 40x of the vegetative and reproductive structures $(\mathrm{D})$ and $(\mathrm{E})$. 

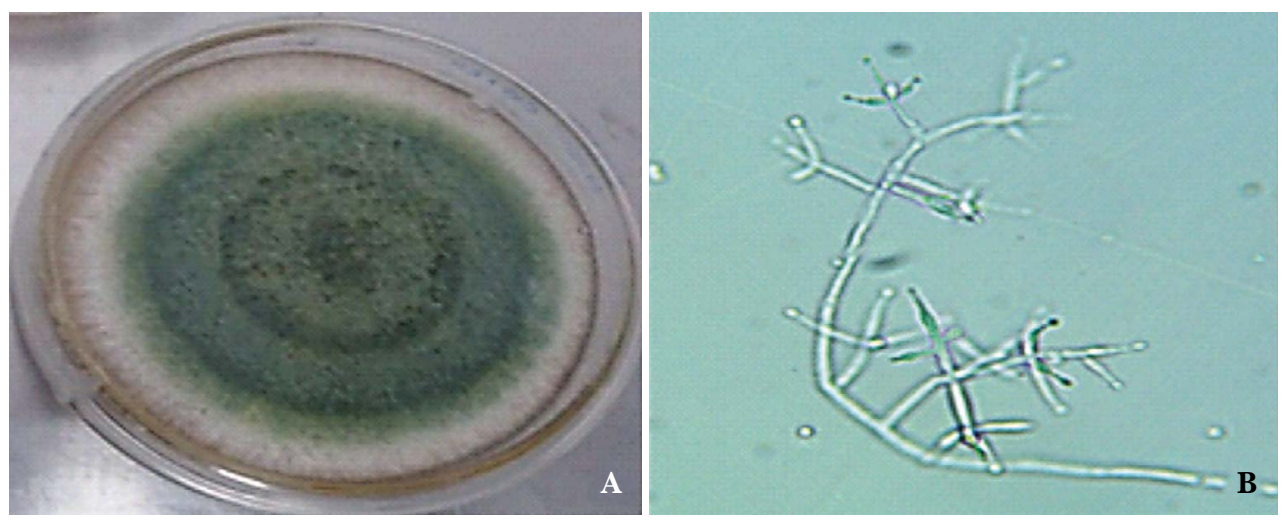

Figure 2. Trichoderma harzianum colony (A) and conidiophores, phialides, and conidia under the microscope (B).

Interaction with the pathogen occurred 72 hours after the dual confrontation test started; after the contact took place, P. belhabhrii stopped growing. After 96 hours, Trichoderma started to cover the pathogen (Figure 3).

Figure 4-A shows that, once T. harzianum's conidia germinated, the hyphae grew towards Peronspora belbahrii's conidiophores, sliding over its surface without penetrating it (chemotrophic growth-search). Under positive chemotropism conditions, Trichoderma grows directly towards the chemical stimulus released by the pathogen (i.e., the first host location phase). Chet and Inbar (1994) proved that Trichoderma can detect the pathogen from a distance and that its hyphae grow towards it. Subsequently, the hyphae of $T$. harzianum started to wound around the conidiophores and hyphae of $P$. belbahrii (Figure 4-B); they developed hook- and appressorium-like structures to hold on to them. Finally, Trichoderma penetrated $P$. belbahrii's hyphae (Figure 4-C) and vacuolation took place (Figure 4-C).

When the penetration process takes place, the antagonist produces extracellular lytic enzymes - mainly, chitinases, glucanases, and proteinases-, which deteriorate the cell



Figure 3. T. harzianum-P. belbahrii in vitro interaction at 96 hours. 


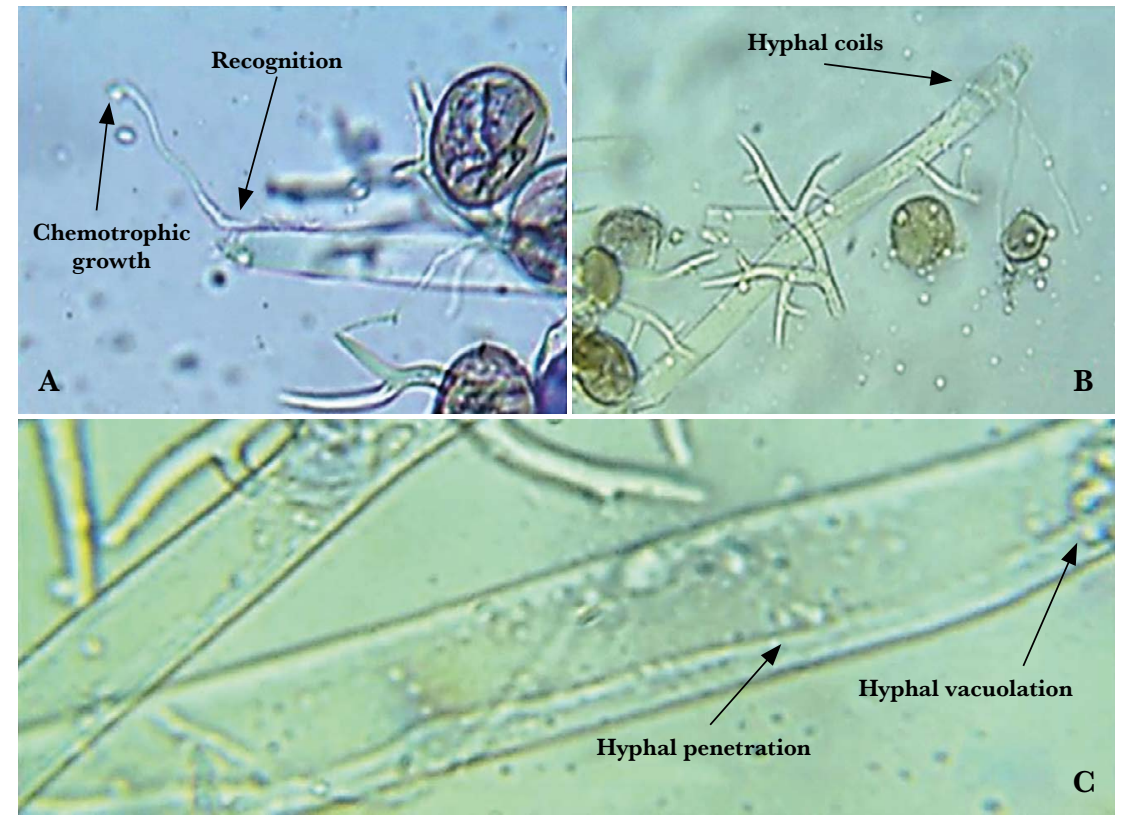

Figure 4. Pictures taken with a 40x optical microscope. The following types of T. harzianum-Peronospora belbahrii hyphal interaction can be seen: chemotrophic growth and search (A); coiling by hyphae (B); penetration and vacuolation $(\mathrm{C})$.

walls of the host and allow the hyphae of the antagonist to penetrate the host (Haram et al., 1996). Martroudi et al. (2009) have also described the antagonism process or mycoparasitic activity of Trichoderma spp. against Sclerotinia sclerotiorum (Lib.) de Bary. Wang et al. (2016) reported that the mycelia of T. harzianum wound around the mycelia of Lentinula edodes (Berk) Pegle, causing the cells to start a lysis process.

\section{CONGLUSIONS}

The pathogenicity test showed that Personospora belbahrii is the mildew causal agent on basil in the study area. Under controlled conditions, the T. harzianum isolation evaluated in this study shows promising signs for the control of Personospora belbahrii in basil. Four types of hyphal interaction showed signs of parasitism: chemotrophic growth and search; coiling by hyphae, penetration, and vacuolation; reduction of mycelial growth; and development of sporangia.

\section{REFERENCES}

Bastidas, M.R., Picazo, L.S., Amador, B.M., Garibay, A.N., Barragan, H.L. \& Montie, L.G.H. (2016). First report of Peronospora belbahrii on sweet basil in Baja California Sur, Mexico. Journal of Phytopathology 164, 122-124.

Belbahri, L., Calmin, G., Lefort, F. \& Pawlowski, J. (2007). Phylogenetic analysis and real time PCR detection of a new Peronospora species responsible for downy mildew disease of sweet basil and sage. Acta Horticulturae 747, 401-408.

Briseño, S., Aguilar, M. \& Villegas, J. (2013). El cultivo de albahaca. Centro de Investigaciones Biológicas del Noreste, S.C. Instituto Politécnico Nacional No. 195 Col. Playa Palo de Santa Rita Sur. La Paz, Baja California Sur. México. 33. https://silo.tips/download/el-cultivo-de-la-albahaca

Chaverri, P., Branco, R.F., Jaklitsch, W., Gazis, R., Degenkolb, T. \& Samuels, G.J. (2015). Systematics of the Trichoderma harzianum species complex and the reidentification of commercial biocontrol strains. Mycologia 107(3), 558-590. 
Chet, I. \& Inbar J. (1994). Biological control of fungal pathogens. Applied Biochemistry and Biotechnology 48, $37-43$.

Choi, Y.J., Choi, I.Y., Lee, K.J. \& Shin, H.D. (2016). Primer informe de mildiu causado por Peronospora belbahrii en albahaca dulce (Ocimum basilicum) en Corea. Plant Disease 100, 2335. doi:org/10.1094/PDIS-05-160771-PDN

Clements, F.E. \& Shear, C.L. (1931). The genera of Fungi. Carnegie state Institution of Washington and United State Department of Agriculture. New York and London: Hafner Publishing Company.

Cohen, Y. \& Ben, N.Y. (2016). El abanico nocturno suprime las epidemias de mildiu en la albahaca dulce. PLoS One. 11 (5), e0155330. doi: 10.1371/journal.pone.0155330.

Cohen, Y., Ben-Naim, Y., Falach, L. \& Rubin, A.E. (2017). Epidemiology of basil downy mildew. Phytopatology 107(10), 1149-1160.

Cohen, Y., Vaknin, M., Ben, N. Y \& Rubin, A.E. (2013). Light suppresses sporulation and epidemics of Peronospora belbahrii. Plos One 8(11), e81282. doi: 10.1371/journal.pone.0081282

Cohen, Y., Vaknin, M., Ben-Naim, Y., Rubin, A. E. \& Galperin, M. (2013). First report of the occurrence and resistance to mefenoxam of Peronospora belbahrii, causal agent of downy mildew of basil (Ocimum basilicum) in Israel. Plant Disease 97, 692. doi:10.1094/PDIS-12-12-1126-PDN

Collina, M., Merighi, M., Turan, G., Pirondi, A., Minuto, G. \& Brunelli, A. (2016). First report of resistance of Peronospora belbahrii, causal agent of downy mildew of basil, to mefenoxam in Italy. Plant Disease 100, 1787. doi:10.1094/PDIS-02-16-0237-PDN

Druzhinina, I.S., Seidl, S.V., Herrera, E.A, Horwitz, B.A., Kenerley, G.M. \& Monte, E. (2011). Trichoderma: the genomics of opportunistic success. Nature Reviewes Microbiology 9, 749-759.

Ellis, D. (2006). Trichoderma. The University of Adelaide Australia. Mycology [Online]. http://www.mycology. adelaide.edu.au/Fungal_Descriptions/Hyphomycetes (hyaline)/Trichoderma

Ghanbarzadeh, B., Safaie, N., Mohammadi, G.E., Rezaee, D.Y. \& Khelghatibana, F. (2016). Biological control of Fusarium basal rot of onion using Trichoderma harzianum and Glomus mosseae. Journal of Crop Protection 5(3), 359-368.

Grabowski, M. (2012). Basil downy mildew Peronospora belbahrii. Regents of the University of Minnesota. University of Minnesota Extension.

Haram, S., Schickler, H.L. \& Chet, I. (1996). Molecular mechanisms of lictin enzymes involved in the biocontrol activity of Trichoderma harzianum. Microbiology 142, 2321-2331.

Harman, G.E. (2006). Overview of mechanisms and uses of Trichoderma spp. Phytopathology 96, 190-194.

Homa, K., Barney, W.P., War, D.L., Wyenandt, C.A. \& Simon. J.E. (2014). Evaluation of fungicides for the control of Peronospora belbahrii on sweet basil in New Jersey. Plant Disease 98, 1561-1566.

Infante, D., Martínez, B.C., González, N. \& Reyes, Y. (2009). Mecanismos de acción de Trichoderma frente a hongos fitopatógeno. Protección Vegetal 24(1), 14-21.

Gisi, U., \& Leadbeater, A. (2010). The challenge of chemical control as part of integrated pest management. Journal of Plant Pathology 92(4), S11-S15.

Lorito, M., Woo, S.L., Harman, G.E. \& Monte, E. (2010). Translational research on Trichoderma: from 'omics to the field. Annual Review of Phytopathology 48, 395-417.

Majorie, R.M., Chaibva, P., Takawira, M. \& Njeni, P. (2016). Evaluation of Trichoderma harzianum in controlling damping-off (Pythium spp) on tomato (Solanum lycopersicum) seedling varieties. Annals of Biological Research 7(6), 6-11.

Martínez, B., González, E. \& Infante, D. (2011). Nuevas evidencias de la acción antagonista de Trichoderma asperellum Samuels. Protección Vegetal 26(2), 131-132.

Martínez, B., Pérez, J., Infante, D., Duarte, Y. \& Moreno, M. (2013). Antagonismo de aislamientos de Trichoderma spp., frente a Didymella bryoniae. Protección Vegetal 28(3), 192-198.

Martínez, G.G.A., Nicolás, S.L., Ortiz, H.Y.D., Morales, I. \& Gutiérrez, H.G.F. (2016). Crecimiento y contenido de aceite en albahaca (Ocimum basilicum L.) bajo mallas sombra de colores. Interciencia 41(6), 428-432.

Martroudi, S., Zamani, M.R. \& Motallebi, M. (2009). Antagonistic effects of three species of Trichoderma sp. on sclerotinia (Sclerotiorum), the causal agent of canola stem rot. Egyptian Journal of Biology 11, 37-44.

Nico, I., Monaco, I., Bello, G. \& Alippi, H. (2005). Efecto de la adición de enmiendas orgánicas al suelo sobre la capacidad patogénica de Rhizoctonia solani: II Micoflora asociada y antagonismo in vitro de los aislados más frecuentes. Revista de Investigaciones Agropecuarias 34(1), 29-44.

Risco, M.A., Apaza, W.E.T. \& Mattos, L.L.C. (2018). Identification of basil downy mildew and severity estimation. Anales Científicos 79 (1), 159-167.

SAGARPA, Secretaría de Agricultura, Ganadería, Desarrollo Rural, Pesca y Alimentación. (2015). Servicio de información agroalimentaria y pesquera. Datos Abiertos. Estadística de Producción Agrícola. http:// infosiap.siap.gob.mx/gobmx/datosAbiertos.php 
Samuels, G.J., Chaverri, P., Farr, D.F \& McCray, E.B. (2007). Trichoderma Online, Systematic Botany \& Mycology Laboratory. http://nt.ars-grin.gov/taxadescriptions/keys/TrichodermaIndex.cfm

Saude, C., Westervel, S. \& Filotas, M. \& McDonald, M.R. (2013). First report of downy mildew caused by Peronospora belbahrii on basil (Ocimum spp.) in Ontario. Plant Disease 97(9), 1248. doi: 10.1094/PDIS01-13-0026-PDN

Sempere, F. \& Santamarina, M.P. (2007). In vitro biocontrol analysis of Alternaria alternata Keissler under different environmental conditions. Mycopathology 163:83-90.

Thines, M., Telle, S., Ploch, S. \& Runge, F. (2009). Identity of the downy mildew pathogens on sage, basil and coleus, with implications for quarantine measures. Mycological Research 113 (5), 532-540.

Wang, G., Cao, X., Ma, X., Guo, M., Liu, C., Yan, L. \& Bian, Y. (2016). Diversity and effect of Trichoderma spp. associated with green mold disease on Lentinula edodes in China. Microbiology Open 5(4), 709-718.

Wyenandt, G.A., Simon, J.E., Pyne, R.M., Homa, K., McGrath, M.T., Zhang S., Raid R.N., Ma L., Wick R., Guo L. \& Madeiras A. (2015). Basil downy mildew (Peronospora belbahrii): discoveries and challenges relative to its control. Phytopathology 105(7), 885-894.

Zhan, G., Thompson, A., Schisler, D. \& Johnson, E.T. (2019). Characterization of the infection process by Peronospora belbahrii on basil by scanning electron microscopy. Heliyon 5(1), e01117. https://doi. org/10.1016/j.heliyon.2019.e01117 